\title{
ANÁLISE DE CONDUTAS E POSTURAS DOS ACADÊMICOS DE ODONTOLOGIA COM PREDISPOSIÇÃO À SÍNDROME DO TÚNEL DO CARPO
}

\author{
ANALYSIS OF BEHAVIORS AND POSITIONS OF \\ THE ODONTOLOGY ACADEMICS WITH A PREDISPOSITION \\ TO THE CARPAL TUNNEL SYNDROME
}

\author{
Anelice Calixto Ruh ${ }^{1}$, Danúbia de Jesus Teider ${ }^{2}$, Sylvio Reynaldo Schleder ${ }^{3}$ \\ 1 CESCAGE. E-mail: <anelicecalixto@yahoo.com.br> \\ 2 CESCAGE \\ 3 UTP PR
}

Recebido para publicação em 08/12/2011

Aceito para publicação em 10/05/2011

\section{RESUMO}

A Síndrome do Túnel do Carpo (STC) é uma compressão nervosa que afeta os membros superiores que pode ser ocasionada por movimentos repetitivos do punho e dedos, extrema flexão e extensão do punho, contração forçada dos tendões que se deslocam pelo túnel, trabalho muscular estático, vibrações, mau posicionamento no trabalho e não conformidades ergonômicas. Por esses fatores se enquadrarem à prática profissional de odontologia, muitos apresentam uma perda da funcionalidade de seu punho e dedos, comprometendo seus atendimentos. Este trabalho objetiva detectar e analisar os métodos e as abordagens utilizadas pelos acadêmicos de Odontologia no modo de realizar seus atendimentos e orientar quanto à prevenção de futura instalação da STC, com a distribuição de material informativo sobre alongamentos dos membros superiores. Foram aplicados questionários a 80 acadêmicos do último ano do curso de Odontologia da UEPG, e do CESCAGE, com faixa etária entre 20 e 25 anos e praticando a disciplina de clínica integrada. $\mathrm{Na}$ amostra pesquisada, $45 \%(\mathrm{n}=36$ acadêmicos $)$ eram do sexo masculino e $55 \%(n=44)$ do sexo feminino. Foram pesquisadas as variáveis em relação à prática de outra atividade profissional, os sintomas correlatos que constam no questionário utilizado no trabalho (Apêndice I), além da realização dos testes específicos (Tínel e Phalen). Após tratamento dos dados estatísticos e acompanhamento nos laboratórios de prática, observou-se que os sintomas que predispõem a STC apresentam prevalência no sexo feminino. Isso se explica devido à realização de outras atividades concomitantes à prática acadêmica e o risco ergonômico, de acordo com o check list para avaliação simplificada do 
risco de ocorrência de Lesões por Esforços Repetitivos/Doenças Osteomusculares Relacionadas ao Trabalho, aponta como resultado altíssimo risco de LER/DORT.

Palavras-chave: Síndrome do Túnel do Carpo. Odontologia. DORT. Ergonomia. Prevenção.

\begin{abstract}
Carpal Tunnel Syndrome (CTS) is characterized by nerve compression that affects the upper limbs that can be caused by repetitive movements of the fist and fingers, extreme flexion and extension of the fist, forced contraction of the tendon that dislocate to the tunnel, static muscular work, vibrations, bad positioning during work activities and not in conformity to ergonomic patterns. These factors are common among Odontology professionals as many professionals present a loss of fist and fingers functionality, compromising the care of patients. The aim of this study is to detect and to analyze the methods and approaches used by Odontology professionals to carry out their activities and to guide them about the prevention of future STC with the distribution of informative material on stretching of the upper limbs. Questionnaires were applied to eighty dentistry students between the ages of 20 to 25 of the last year of the dentistry course from the UEPG and CESCAGE universities. These students were taking the disciplines of integrated clinic. In the sample, $45 \%(n=36$ students) were male and $55 \%(n=44)$ were female. The variable in relation to the practice one of another professional activity had been searched, the symptoms mentioned in the questionnaire used in the study (Appendix I), in addition to specific tests (Tínel and Phalen). After treatment of the statistical data and follow up in the practical classes, it was observed that the STC symptoms prevail in female students with a predisposition to the syndrome. This can be explained as other activities were carried out at the same time of the practical activities and the ergonomic risk according to a check list for simplified evaluation of the risk of Repetitive Strain Injuries/Osteomuscular Disease Related of the Job occurrence. The results indicate a very high risk of RSI/DRJ.
\end{abstract}

Keywords: Carpal Tunnel Syndrome. Odontology. DORT. Ergonomics. Prevention.

\section{Introdução}

A mão representa o ponto distal de um sistema de extrema complexidade, no qual estão envolvidos músculos, tendões e ramificações nervosas, cujo resultado final é a conjugação perfeita e harmônica de movimentos que vão desde a grande intensidade de força existente numa preensão forte de um alicate até a mínima força exercida ao se fazer uma microcirurgia (COUTO, 1996; GRANDJEAN, 1998).

Este complexo arranjo anatômico e funcional é muitas vezes mal utilizado na rotina de trabalho. O mau uso das mãos pode ocasionar as lesões por traumas cumulativos (LTC) dos membros superiores, que geralmente são o somatório de esforços e traumas repetitivos, em grande intensidade (COUTO, 1996; GRANDJEAN 1998).

O Túnel do Carpo é ocupado pelo nervo mediano, tendões flexores dos dedos e polegar. $\mathrm{O}$ arco cárpico é relativamente estável; forma a base para a movimentação dos dedos, bem como o assoalho do túnel carpiano, que fornece suporte e proteção para tendões flexores dos dedos e nervo mediano (GOLD, 1998).

A Síndrome do Túnel do Carpo (STC) é a mais comum das compressões nervosas e a mais bem conhecida patologia que afeta as 
extremidades superiores (MARTINS, 2003). Apresentando como fatores responsáveis pelo seu aparecimento: movimentos repetitivos de alta velocidade do punho e dedos; extrema flexão e extensão do punho; contração forçada dos tendões que se deslocam pelo túnel; trabalho muscular estático; posições extremas da mão no trabalho; estresse mecânico do nervo mediano na base da palma; vibrações; e luvas ajustadas de maneira inadequada (MARTINS, 2003).

A atividade profissional de cirurgiões-dentistas os obriga a utilizar como rotina de trabalho os membros superiores, principalmente as mãos, com repetitividade de um mesmo padrão de movimento, e compressão mecânica das estruturas localizadas na região (REGIS, 1997).

Outro fator importante, é que são comuns os casos de inadequação operador/equipamento/ instrumento nas áreas da saúde, obrigando o profissional a assumir posturas incorretas de trabalho, o que causa microtraumatismos, cujo somatório pode originar as tecnopatias odontológicas, como as Lesões por Esforços Repetitivos (LER) (REGIS, 1997, 2004).

Por esses fatores se enquadrarem com a prática profissional de odontologia, muitos apresentam uma perda da funcionalidade de seu punho e dedos, comprometendo sua atuação profissional e qualidade de vida.

A particularidade da prática odontológica em ser diária e a presença de atividades repetitivas demonstram como há um aumento dos sintomas relacionados à adoção de posturas do acadêmico durante $\mathrm{o}$ atendimento, o que torna mais suscetível o surgimento de determinadas patologias (REGIS, 1997).

Esta pesquisa tem como objetivo principal: detectar e analisar os métodos e as abordagens utilizadas pelos acadêmicos de Odontologia através de observação e fotos demonstrativas na realização de seus atendimentos; e como objetivos secundários: a orientação para prevenção de futura instalação da Síndrome do Túnel do Carpo com a distribuição de material informativo sobre alongamentos dos membros superiores, bem como, levantamento ergonômico do posto de trabalho (check list-Anexo III).

\section{Materiais e métodos}

A presente pesquisa, quanto ao sentido metodológico, é classificada como tipicamente de campo e de caráter qualitativo, em que se procurou definir, sob o enfoque ergonômico, o perfil epidemiológico em relação à Síndrome do Túnel do Carpo.

Foram pesquisados 80 acadêmicos de Odontologia do último ano do Centro de Ensino Superior dos Campos Gerais. Estavam divididos em dois grupos de 10 acadêmicos e da Universidade Estadual de Ponta Grossa, que estavam divididos em três grupos de 20 acadêmicos, tal pesquisa foi realizada na cidade de Ponta Grossa, Paraná e todos os acadêmicos e coordenadores de curso assinaram os termos de consentimento e de autorização para sua realização.

Os questionários (Apêndice I) foram elaborados e realizados pelas autoras uma única vez com 80 acadêmicos participantes da disciplina prática de Clínica Integrada nos dias de aula de cada grupo. Estes objetivavam buscar informações sobre os aspectos qualitativos referentes à Síndrome do Túnel do Carpo, e eram compostos de três partes: uma destinada ao perfil sócio cultural do entrevistado; outra parte relativa às questões epidemiológicas propriamente ditas; e a última parte era relativa aos Testes de Tínel e de Phalen.

Segundo Magee (2005), o Teste de Tínel consiste em o examinador realizar a compressão durante um minuto sobre o túnel do carpo no punho. Um teste é considerado positivo quando desencadeia parestesia nos dedos polegar, indicador, médio e na porção lateral do anular (distribuição do nervo mediano). A parestesia 
deve ser sentida distalmente ao ponto de pressão. $\mathrm{O}$ teste fornece uma indicação sobre a velocidade de regeneração das fibras sensitivas do nervo mediano. O Teste de Tínel no punho é indicador da Síndrome do Túnel do Carpo.

No Teste de Phalen o examinador realiza a flexão dos punhos do paciente ao máximo e mantém a posição durante um minuto, aproximando-os. O teste é considerado positivo quando ocorre parestesia nos dedos polegar, indicador, médio e na porção lateral do anular, e é indicativo da Síndrome do Túnel do Carpo causada por compressão do nervo mediano (MAGEE, 2005).

Para a presente pesquisa utilizou-se do check list para a avaliação simplificada do risco de ocorrência de LER/DORT (Anexo III), que ajuda a diagnosticar de maneira simples e ordenada os diferentes fatores de risco existentes. Também foram realizadas fotos demonstrativas (Anexo IV) para análise ergonômica das posturas dos acadêmicos durante seus atendimentos, utilizando-se câmera digital marca OLYMPUS, 5.0 megapixel, FE 115/X-715.

Após o término da coleta de dados foi entregue a cada acadêmico um material com exercícios de alongamentos para membros superiores (Anexo $\mathrm{V}$ ), onde todos foram orientados a realizá-los antes, durante e após os atendimentos, com o objetivo de prevenção de uma futura instalação da STC.

Os estudos da ergonomia preventiva procuram dar ao homem a possibilidade de produzir um trabalho eficiente, menos cansativo e com melhor qualidade de vida, ao mesmo tempo utilizando equipamentos e instrumentos cada vez mais aperfeiçoados, além da correção de posturas inadequadas, prevenindo ainda mais problemas futuros (RASIA, 2004). Esses alongamentos melhoram a circulação e relaxam as áreas tensas, preservando a saúde e otimizando a qualidade de vida dos seus praticantes (POI, 1999).O objetivo maior é obter flexibilidade das articulações dos ombros, cotovelos, punhos e dedos, pois assim se possibilita a melhora da circulação sanguínea dos tecidos musculares e cartilaginosos e se regulam as funções dos nervos (POI, 1999).

Os exercícios para membros superiores são indicados para a prevenção de tenossinovites, tendinites, sinovites, miosites, fascites, epicondilites, paralisia dos membros superiores, dormência nas mãos e lesões por esforços repetitivos (POI, 1999).

Nachenson, em 1971, evidenciou que na posição sentada a pressão nos discos intervertebrais é $50 \%$ maior que na posição de pé. Trabalhar sentado pode originar uma série de dores e complicações (GRANDJEAN, 1998; COUTO, 1995). Para se superar essa contradição o melhor é sentar-se bem, numa cadeira projetada ergonomicamente, numa relação cadeira-mesa-acessórios adequada (IIDA, 1997; GRANDJEN, 1998; COUTO, 1995).

A mais importante alteração é o aumento (cerca de 50\%) na pressão dos discos intervertebrais da coluna lombar. O disco intervertebral não possui nutrição por artérias e o aumento em sua pressão interna reduz sua taxa de nutrição, aumentando sua degeneração (IIDA, 1997; GRANDJEN, 1998; COUTO, 1995).

A inclinação do tronco para frente acarreta a queda de todo o corpo, devido à ação da gravidade. Para equilibrar este esforço e manter o tronco ereto os músculos paravertebrais realizam contração estática e por estarem fixados nos corpos vertebrais, aumentam a pressão nos discos lombares (IIDA, 1997; GRANDJEN, 1998; COUTO, 1995).

O apoio para as costas é extremamente importante para a diminuição das pressões intradiscais e consequentemente diminui a chance de lesões. A melhor postura para o disco e para os músculos paravertebrais é quando o tronco e coxas estão formando um ângulo de 100, $110^{\circ}$ (IIDA, 1997; GRANDJEN, 1998; COUTO, 1995).

Os músculos do pescoço, numa inclinação excessiva da cabeça, resultam em esforço estático 
e fadiga. $\mathrm{O}$ ângulo de maior conforto é quando o ângulo da visão está próximo de 37 (IIDA, 1997; GRANDJEN, 1998; COUTO, 1995).

A distribuição ideal dos pesos na posição sentada é: $50 \%$ no quadrângulo do ísquio (base da bacia); $34 \%$ na região posterior das coxas; e $16 \%$ na planta dos pés. Sentado é mais difícil para o sangue subir das pernas e pés de volta para o coração, situação mais crítica quando existem más condições ergonômicas (IIDA, 1997; GRANDJEN, 1998; COUTO, 1995).

A ergonomia da cadeira de trabalho deve ser estofada com tecido que permita a transpiração. Sua altura dever ser regulável e a dimensão antero-posterior do assento deve ser uma em que as coxas fiquem apoiadas, mas sem compressão na região posterior do joelho. A borda anterior do assento deve ser arredondada; o assento deve estar na posição horizontal; e deve se inclinar de $10 \mathrm{a}$ $15^{\circ}$ para frente. Além disso, toda cadeira deve ter apoio para o dorso; o ângulo entre o assento e o apoio deve ser regulável; o apoio do dorso deve ter uma forma que acompanhe as curvas da coluna; $o$ apoio também deve ser regulável; é preciso haver espaço na cadeira para apoiar as nádegas; a cadeira deve ser giratória; os pés devem ficar apoiados; e é preciso existir espaço para as pernas debaixo da mesa (IIDA, 1997; GRANDJEN, 1998; COUTO, 1995).

O organismo humano possui alguns mecanismos naturais de recuperação e que ajudam a prevenir a ocorrência de lesões. São eles: pausa (realizada durante um esforço físico) e efeitos hormonais (durante o sono, há liberação do hormônio somatotrófico-STH - promovendo o crescimento de tecidos sadios) (COUTO, 1996; GRANDJEAN, 1998).

Os membros superiores passaram a ser elementos de realização da atividade útil, principalmente através da utilização das mãos. Das suas funções no trabalho, as mãos atuam como elementos de preensão, de pinçamento ou de pressão (COUTO, 1996; GRANDJEAN, 1998). A função de preensão é aquela que dá às mãos maior capacidade de força. E a função de pinça não nos habilita ao desenvolvimento de muita força, mas nesse tipo de atividade o que mais se caracteriza é a precisão do movimento (COUTO, 1996; GRANDJEAN, 1998).

Os membros superiores, e particularmente as mãos e pontas dos dedos, são algumas das áreas mais inervadas do nosso corpo. Essa inervação, tanto motora quanto sensitiva, é capaz de fazer o controle neurovegetativo, principalmente da vascularização e das glândulas sudoríparas das palmas das mãos, que ajudam a manter um grau adequado de atrito entre a mão e a superfície tocada (COUTO, 1996; GRANDJEAN, 1998).

A inervação dos membros superiores é feita por um conjunto de três nervos com funções distintas: nervo mediano, radial e ulnar (COUTO, 1996; GRANDJEAN, 1998).

No trajeto do membro superior os três nervos que apresentam pontos críticos são: a passagem do nervo ulnar no cotovelo, bem externo e bem junto dos ossos do cotovelo; passagem do nervo mediano no túnel do carpo, passando do antebraço para a mão; as ramificações periféricas dos três nervos juntos dos dedos, em suas porções laterais; e a saída do nervo mediano na base da mão (COUTO, 1996; GRANDJEAN, 1998).

A compressão do nervo mediano na base da palma da mão por ferramentas e por vibração é causada mais comumente por ferramentas inadequadas cuja base se apoia sobre a base da palma da mão; concentração de força na base da mão; uso frequente de alta intensidade de força; e vibração (COUTO, 1996; GRANDJEAN, 1998).

Os sintomas são os de acometimento do nervo mediano, principalmente alterações da sensibilidade e alterações da função motora (COUTO, 1996; GRANDJEAN, 1998). 
O túnel do carpo é um canal existente na face palmar do punho, por onde, num espaço relativamente folgado, passam diversos tendões, ao lado do nervo mediano. Em circunstâncias normais, o nervo passa nesse túnel livre, sem compressões, mas sob certas circunstâncias o espaço pode se tornar estreito, que ocorre por exigência de flexão e extensão do punho e tenossinovite ao nível dos tendões dos flexores (COUTO, 1996; GRANDJEAN, 1998).

As lesões por traumas cumulativos nos membros superiores são decorrentes das interações inadequadas de quatro fatores biomecânicos principais: força; posturas incorretas dos membros superiores (pescoço excessivamente estendido e/ou fletido; braços abduzidos e/ou elevados acima do nível dos ombros; membros superiores suspensos por muito tempo; sustentação estática dos antebraços pelos braços; flexão e/ou extensão exagerada do punho; desvio lateral da mão); repetitividade; e compressão mecânica (COUTO, 1996; GRANDJEAN, 1998).

A força de trabalho dependerá do peso absoluto do objeto e da posição em que este está sendo manipulado em relação ao eixo do corpo. Em função das posições do braço em alavanca, a manipulação de objetos ou ferramentas de pouco peso pode exigir esforços importantes e aumentar o risco para as articulações do ombro e cotovelo. O grau de nocividade da força depende da posição do objeto em relação ao corpo, do tempo de manutenção, da frequência, da forma da ferramenta manipulada, do uso de luvas ou de ferramentas vibrantes e das posturas de pega ou agarre (LEÃO e PERES, 2004).

Malchaire e Cock (1995) (apud LEÃO e PERES, 2004) definem repetitividade como sendo o número de passagens, por unidade de tempo de uma situação neutra a má situação extrema em termos de movimentos angulares, de força ou ainda de movimentos e força.
Kilbom, (1994) separa repetitividade por partes do corpo, ombro acima de $21 / 2$, braço/cotovelo/ antebraço e punho acima de 10 e dedos acima de 200 repetições por minuto (apud LEÃO e PERES, 2004).

Fatores contributivos para as lesões dos membros superiores são: tensão excessiva; frio; vibração; gênero (mulheres são de duas a três vezes mais predispostas a tais lesões, pois apresentam menor resistência das estruturas, inter-relação com hormônios-estrógenos, cargas extras de trabalho proveniente das atividades domésticas); trabalhar com postura tensa; e desprazer (COUTO, 1996; GRANDJEAN, 1998).

A exposição a vibrações mano-braquiais foi relacionada com aumento da força de preensão necessária na manutenção de equipamentos vibrantes, aumentando desta forma a probabilidade de desenvolver distúrbio osteomuscular, principalmente ao nível do punho e mãos. Outros fatores são a utilização de luvas de proteção, já que isto reduz a sensibilidade táctil, o que acarreta um aumento da força de preensão (LEÃO e PERES, 2004).

Para a eficácia da ação ergonômica, parte-se do conhecimento das causas das lesões e trata-se de organizar uma melhoria nos postos de trabalho, atacando cinco fatores mais cruciais: força manual excessiva; posturas incorretas dos membros superiores; alta repetitividade de movimentos; compressão mecânica das estruturas; e tensão excessiva no trabalho (COUTO, 1996; GRANDJEAN, 1998).

Deve-se reduzir a força necessária para a realização do trabalho que não deve exigir mais que $30 \%$ da capacidade de força de um determinado grupamento muscular de forma prolongada ou repetitiva. Deve-se evitar qualquer contração muscular envolvendo um esforço maior que 50\% do máximo de força do músculo, mesmo se feita ocasionalmente. Utilizam-se três recomendações 
básicas como: reduzir a força necessária; espalhar a força; e obter vantagem mecânica (COUTO, 1996; GRANDJEAN, 1998).

Deve-se reduzir ou eliminar posturas incorretas da cabeça e dos membros superiores. Os movimentos que são feitos com grande freqüência precisam ser mantidos dentro dos limites razoáveis de movimentos daquela articulação. Assim, quando a força estiver sendo aplicada pela mão, o punho deve estar retificado e o cotovelo no ângulo correto (COUTO, 1996; GRANDJEAN, 1998).

Há pelo menos seis métodos para reduzir os desvios posturais: colocar os objetos dentro da área de alcance (os objetos/ferramentas a serem usados de forma frequente deverão estar dentro da área de alcance normal); mudar a ferramenta ou controle (curvar a ferramenta, não o punho); mudar o componente (rodar a parte que esteja em frente ao trabalhador, de forma que o punho se mantenha retificado); mudar a posição do trabalhador em relação ao componente; apoiar o segmento corpóreo que não esteja na posição neutra; dotar o posto de trabalho de regulagem de altura (trabalhar sentado: colocar cadeiras de regulagem fácil de altura, garantindo que exista apoio adequado para os pés do trabalhador) (COUTO, 1996; GRANDJEAN, 1998).

Adotar medidas para reduzir o grau de repetição enriquecendo a tarefa (reestruturação da tarefa de modo a que cada trabalhador tenha um número maior e mais variado de tarefas para desenvolver); mecanização (uso de ferramentas especiais dotadas de equipamentos motorizados); automação (tarefas de alta repetitividade são desenvolvidas melhor por máquinas); revezamento nas funções (promover rodízio nas tarefas percebidas como de alta repetitividade); pausas (devem ser de 5 a 10 minutos por hora); e exercícios de alongamentos musculares (melhorar nutrição dos músculos) (COUTO, 1996; GRANDJEAN, 1998).
Redução da compressão mecânica no cotovelo (uso de almofadas para apoiar os cotovelos; canto da bancada de trabalho arredondado); redução da compressão nas mãos (manoplas de diâmetro adequado $20-35 \mathrm{~mm}$ de forma cilíndrica e cobertas de plástico semideformável ou de espuma; e utilização da redução do grau de tensão no trabalho, proporcionando bem-estar ao trabalhador (COUTO, 1996; GRANDJEAN, 1998).

Para o presente estudo, foram selecionados indivíduos de ambos os sexos, com idades entre 20 e 25 anos, realizando a prática na disciplina de Clínica Integrada, e que estivessem cursando o último ano de Odontologia. Foram excluídos acadêmicos de Odontologia de anos anteriores, com idade abaixo de 20 anos e acima de 26 anos, que estivessem realizando a prática em outras disciplinas e acadêmicos que apresentassem deformidades e/ ou fraturas em ombro, punhos e dedos.

Para a realização do método estatístico, construção de gráficos em colunas e tabelas foi utilizado o programa Excel do Windows 98.

\section{Resultados}

A primeira parte do questionário procurou determinar o perfil do acadêmico com relação ao sexo, idade, dominância da mão, realização de outra atividade profissional e prática de atividade física ou hobby.

Na amostra pesquisada, $45 \%$, ou seja, 36 acadêmicos eram do sexo masculino e $55 \%$, ou seja, 44 acadêmicos do sexo feminino.

Em relação à faixa etária, esta se apresenta como um critério de inclusão, sendo consideradas as idades entre 20 e 25 anos, de ambos os sexos.

$\mathrm{Na}$ análise sobre a dominância da mão direita e esquerda, o estudo não constatou diferença significativa entre os sexos (Figura 1). 
Figura 1 - Porcentagem de acadêmicos segundo dominância da mão.
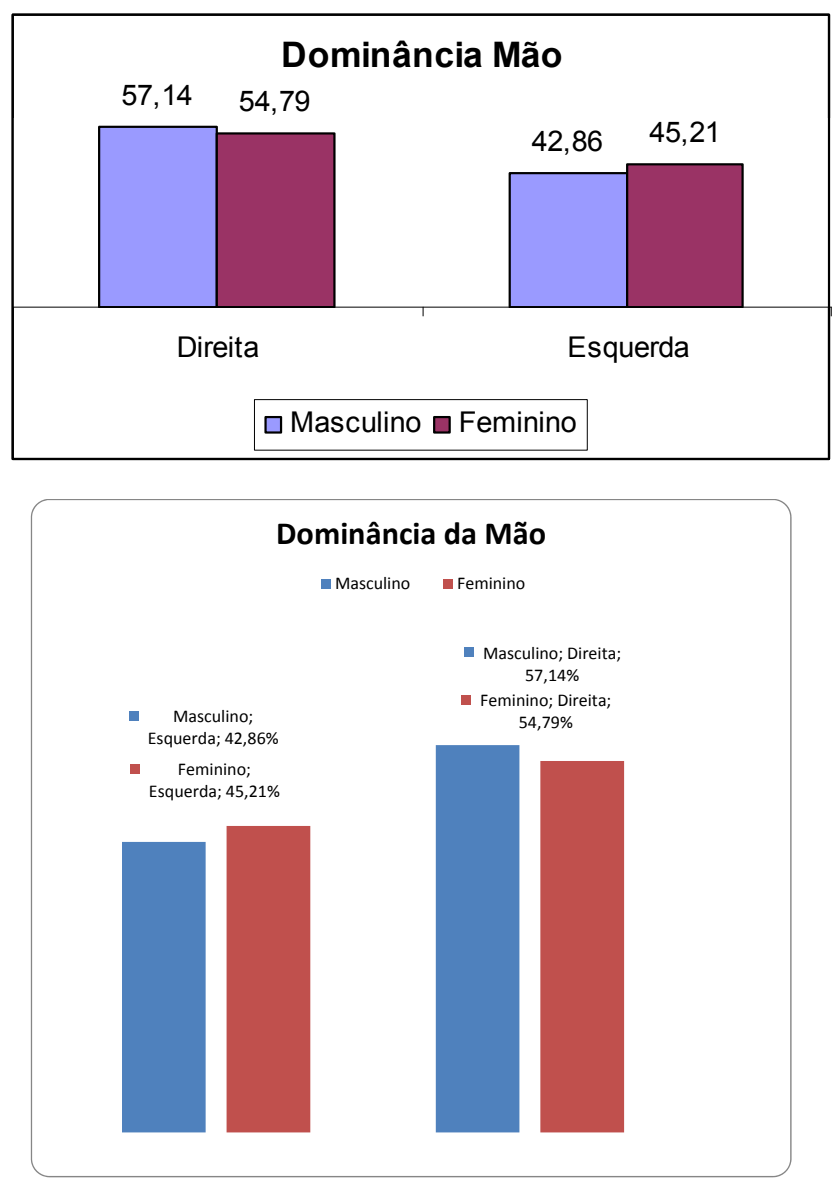

O quarto fator pesquisado foi a prática concomitante de outra atividade profissional. A distribuição para os acadêmicos do sexo masculino e feminino encontra-se evidenciada na Tabela 1.

Tabela 1 - Porcentagem de acadêmicos, sexo masculino e feminino, segundo outra atividade profissional (2006)

\begin{tabular}{ccc}
\hline $\begin{array}{c}\text { Outra Atividade } \\
\text { Profissional }\end{array}$ & Masculino (\%) & Feminino (\%) \\
\hline Protético/a & 40 & 20 \\
\hline Professor/a & 20 & 60 \\
\hline Digitador/a & 0 & 20 \\
\hline Vendedor/a & 40 & 0 \\
\hline Total & 100 & 100 \\
\hline
\end{tabular}

Foi investigada também a prática da atividade física ou hobby e constatou-se que a maioria frequenta academia, joga futebol ou faz caminhada (Figura 2).
Figura 2 - Porcentagem de acadêmicos segundo atividade física (2006)

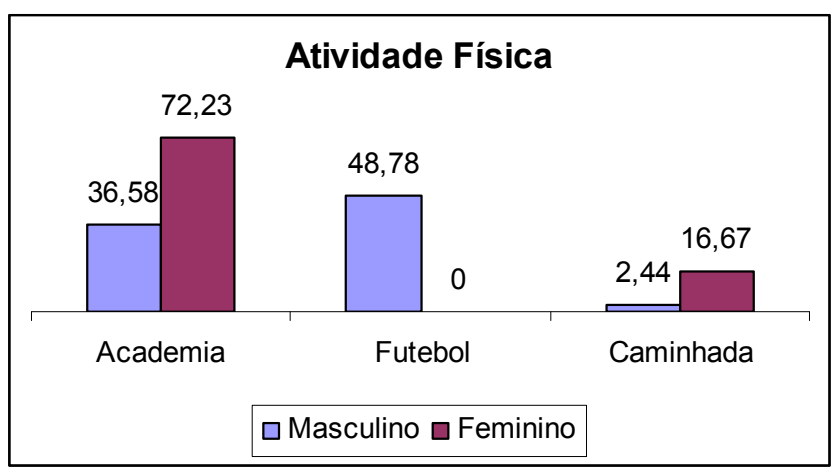

Notamos que no Teste de Tínel há uma prevalência elevada de positividade em acadêmicos do sexo feminino, com diferença não significativa entre as mãos, sendo prevalente a negatividade entre os acadêmicos do sexo masculino (Figura 3).

Figura 3 - Porcentagem de acadêmicos segundo Teste de Tínel
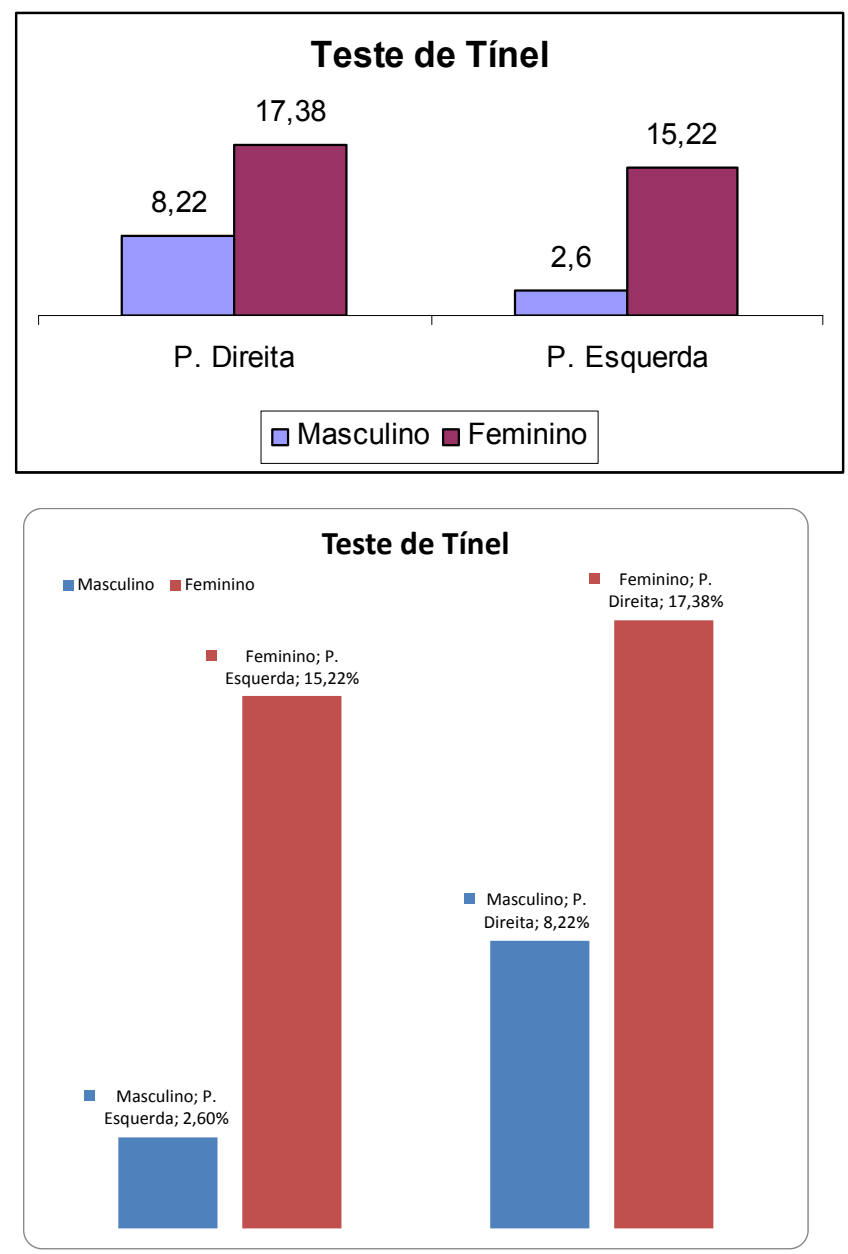
No Teste de Phalen verificou-se que há uma maior positividade em mão direita no sexo feminino e em mão esquerda no sexo masculino. Notamos que não há diferença significativa entre a negatividade do teste com relação ao sexo (Figura 4).

Figura 4 - Porcentagem de acadêmicos segundo Teste de Phalen
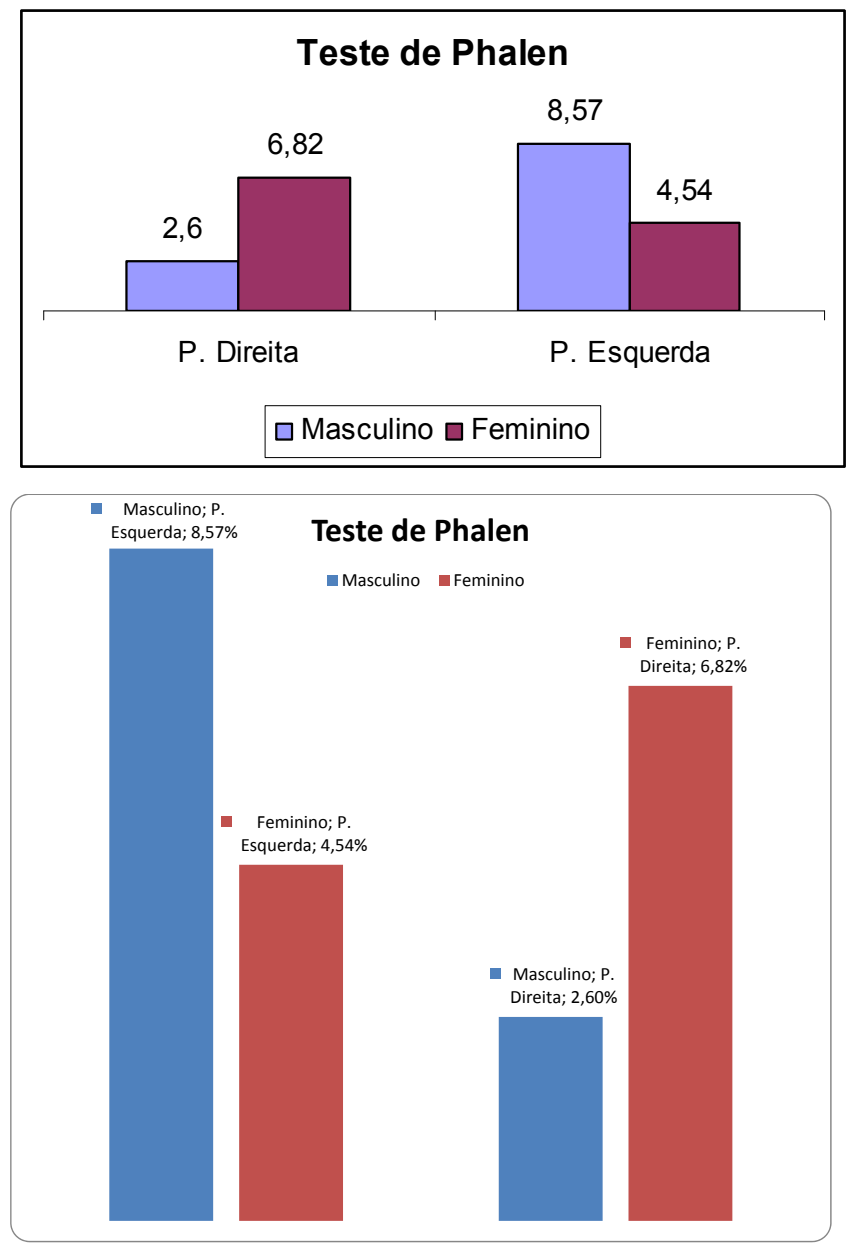

A prevalência de determinados sintomas (acordar no meio da noite com dor, parestesia em toda a mão, dor na região cervical e dor na coluna torácica) é mais patente no sexo feminino. Edema/ dor na região do punho, dor irradiada para o braço e ombro, sem sintomas, são mais evidentes no sexo masculino. Quanto à dor na coluna lombar não existe prevalência com relação ao sexo (Tabela 2).
Tabela 2 - Porcentagem de acadêmicos segundo Sintomas

\begin{tabular}{ccc}
\hline Sintomas & $\begin{array}{c}\text { Masculino } \\
(\mathbf{\%})\end{array}$ & $\begin{array}{c}\text { Feminino } \\
\mathbf{( \% )}\end{array}$ \\
\hline Dor noturna & 4,45 & 13,43 \\
\hline Parestesia & 0 & 4,48 \\
\hline Edema/dor & 8,89 & 5,97 \\
\hline Dor cervical & 11,11 & 35,82 \\
\hline Irradia braço & 13,33 & 4,48 \\
\hline Dor torácica & 2,22 & 7,46 \\
\hline Dor lombar & 13,23 & 14,93 \\
\hline Assintomático & 46,67 & 13,43 \\
\hline
\end{tabular}

O check list utilizado para análise de sobrecarga física, força com as mãos, postura no trabalho, posto de trabalho, repetitividade e ferramenta de trabalho é graduado com valores acima de 22 pontos (baixíssimo risco de LER/DORT) e abaixo de 11 pontos (altíssimo risco de LER/DORT). Depois da análise da pontuação dos itens do check list obteve-se um resultado final de 10 pontos, o que indica altíssimo risco de ocorrência de LER/ DORT.

$\mathrm{Na}$ análise das fotos demonstrativas observou-se que as posturas mais utilizadas pelos acadêmicos durante seus atendimentos foram a postura de flexão de cervical e tronco, flexão e extensão do punho, movimento de pinça, utilização de instrumento vibratório e posição sentada inadequada.

\section{Discussão}

De acordo com a análise dos resultados obtidos nesta pesquisa constatou-se que a maioria dos acadêmicos é do sexo feminino (55\%), concordando com a autora Andréia Faria (2003), que, no seu artigo Riscos no trabalho de cirurgiõesdentistas: Informações e práticas referidas, fala das características pessoais dos entrevistados, onde há uma discreta predominância do sexo feminino sobre o masculino. Outros trabalhos com cirurgiões-dentistas também têm demonstrado 
percentuais maiores para o sexo feminino em relação ao masculino (AGUÍRRE, 1993).

Como se observa na Tabela I, há uma forte concentração de acadêmicos do sexo feminino com outra atividade profissional (60\% professoras). Conforme Andréia Faria (2003) cita em sua tese, a maioria dos entrevistados $(74 \%)$ exerce ou já exerceu alguma outra atividade profissional além do consultório odontológico particular em que estavam sendo entrevistados. Destes, um pouco mais da metade deles $(51,4 \%)$ atua também como cirurgiões-dentistas em outros locais, e 29,7\% como professores universitários.

Segundo Regis Filho e Lopes (1997), a LER incide mais em mulheres, devido à jornada doméstica, pelo menor número de fibras musculares, e pela menor capacidade de armazenar e converter glicogênio em energia útil. Couto (1996) cita ainda que as mulheres são de duas a três vezes mais predispostas a estas lesões por apresentarem menor resistência das estruturas, inter-relação com hormônios-estrógenos, e cargas extras de trabalho proveniente das atividades domésticas.

Em relação aos dados encontrados com a aplicação dos testes de Tínel e de Phalen, chegou-se a uma maior negatividade em ambos os sexos, sem dados compatíveis para discussão na literatura.

De acordo com os questionários aplicados aos acadêmicos relacionados aos sintomas, constatou-se que $35,82 \%$ apresentavam dor em região cervical; $14,93 \%$ dor em coluna lombar; 13,33\% no braço e no ombro; $8,89 \%$ dor no punho; e $7,46 \%$ dor em coluna torácica.

Em uma amostra (OLIVEIRA; GONÇALVES, 2003) de 17 indivíduos, 12 relataram a presença de dor, sendo, dor no ombro: um indivíduo; dor nas costas: 3 indivíduo; dor no joelho: um indivíduo; dor no tornozelo: um indivíduo; dor lombar: três indivíduos; dor torácica: dois indivíduos; dor nas pernas: um indivíduo; dor nos braços: dois indivíduos; dor no pescoço: um indivíduo e dor na coluna: um indivíduo.

Em pesquisa realizada com cirurgiõesdentistas formados entre os anos de 1986 e 1997 (RUCKER; SUNELL,2002), em British Columbia, no Canadá, verificou-se que $9 \%$ dos que responderam ao questionário afirmavam terem tido dores nas mãos relacionadas ao trabalho. Aproximadamente $18 \%$ relataram dores nos ombros; $24 \%$, dores no pescoço; 19\%, em coluna cervical; $30 \%$ na coluna torácica; e $17 \%$ na região lombar (RASIA, 2004).

O risco ergonômico é a razão de vários estudos entre os cirurgiões-dentistas, tais como em Barros (1991, 1993, 1995); Caldeira (2000), que estudou distúrbios osteo-musculares relacionados ao trabalho na prática odontológica; Capriglione (1998); Castro (1999); Figlioli (1998); Lopes (1994), que relacionou a incidência da Síndrome do Túnel do Carpo de caráter ocupacional com os procedimentos odontológicos; e ainda Orenha (1998); Porto (1997); Saguy (1994, 1996); Saliba (1998) e Silva (1994), para citar apenas alguns. As queixas posturais concentraram-se principalmente nos membros superiores e coluna vertebral, as porções consideradas mais envolvidas na execução do trabalho (AGUÍRRE, 1993).

No check list para avaliação simplificada do risco de ocorrência de LER/DORT, chegou-se à conclusão de que há um altíssimo risco de LER/ DORT (obtendo-se um valor abaixo de 11 pontos).

No trabalho de Andréia Faria (2003), citado anteriormente, o ambiente físico utilizado por seus entrevistados recebeu aprovação de $78 \%$ a 92\%; porém, existiam queixas com relação à operação dos instrumentos, que eram considerados pesados. Já em trabalho realizado por Orenha (1999), foi proposto um modelo de avaliação ergonômica das salas de atendimento e quantificou-se o nível de satisfação ergonômica obtendo resultado de $75 \%$ de alas com nível regular (AGUÍRRE, 1993). 
Ainda de acordo com Andréia Faria (2003), as condições de trabalho podem determinar e condicionar a aparição e distribuição de enfermidades nos cirurgiões-dentistas, como demonstrado no trabalho de Santos Filho e Barreto (2001) apud Aguírre (1993) em que os autores estudaram os quadros de lesões músculo-esqueléticas desses profissionais e afirmaram que tais lesões "abrangem componentes do processo de trabalho, englobando a atividade repetitiva, monótona e o esforço físico-postural, aspectos da organização do trabalho e fatores psicossociais" além de que "parece também haver indicadores de estresse e sintomas músculo-esqueléticos".

Rasia, (2004) em concordância com o trabalho de Regis Filho (2004), mais recentes a respeito de DORT em cirurgiões-dentistas, descreve sintomas de dor e desconforto em diferentes regiões do segmento superior do corpo e coloca estes profissionais entre os primeiros lugares em afastamento do trabalho por incapacidade temporária ou permanente, respondendo por cerca de $30 \%$ das causas de abandono prematuro da profissão.

Uma pesquisa realizada no estado de São Paulo (OHASHI, 2002) demonstrou que 60\% dos cirurgiões-dentistas alegam sentir dores após um dia de trabalho e que $15,5 \%$ destes afirmaram ter adquirido alguma doença em decorrência da atividade odontológica. A atividade do cirurgiãodentista (ROBRAC, 1998; CASTRO; FIGLIOLI, 1999) requer movimentos repetitivos, sendo mais evidente quanto mais especializada for sua atuação (periodontistas e endodontistas), o que o predispõe (CASTRO; FIGLIOLI, 1999) a doenças osteomusculares (RASIA, 2004).

Os distúrbios mais evidentes (MICHELIN et al, 2000; LADERAS; FELSENFELD, 2002) incluem a Síndrome do Túnel do Carpo, tendinites e problemas de pescoço e coluna. Pelo trabalho sentado, característico da odontologia, há tendência ao surgimento de varizes nas pernas. No entanto, esse número é superado por problemas na coluna cervical e braços, podendo, ainda, estar relacionado com as tensões excessivas e à insatisfação no trabalho, o que pode gerar estresse. Confirmou-se mediante pesquisa, realizada por Michelin et al (2000), a alta prevalência de dores lombares, desconforto no pescoço e ombro, além de dores em regiões como quadris, pernas, punhos e mãos (Apud RASIA, 2004).

As primeiras contribuições da ergonomia no campo da odontologia destinaram-se a melhorar as condições de trabalho, criando e aperfeiçoando as ferramentas, instrumentos e mobiliário utilizados por esses profissionais. Na revisão da literatura sobre ergonomia na odontologia não foram encontrados estudos ergonômicos voltados para a análise da atividade (RASIA, 2004).

De acordo com a literatura neste trabalho, durante a análise das fotos demonstrativas também se verificou que os movimentos mais utilizados pelos acadêmicos que predispõem à Síndrome do Túnel do Carpo são flexão e extensão excessiva, com desvio radial e ulnar do punho, movimento de pinça com contração estática de indicador e polegar, utilização de luvas que diminuem a sensibilidade de contato e a utilização de instrumentos vibratórios.Além da adoção de posturas de flexão de cervical e tronco, encontrou-se também flexão e abdução excessiva de membros inferiores, falta de apoio dos pés, compressão de tecidos moles e utilização inadequada do mobiliário.

Para o cirurgião-dentista obter melhor acesso e visibilidade em seu trabalho, são preconizadas diversas posições e posturas, além de diferentes regiões de apoio das mãos para a execução dos procedimentos clínicos, segundo Andréia Faria (2003).

A ergonomia sugere que a maneira mais favorável de se trabalhar (FINKBEINER, 2001; BARROS, 1995) é com o "trabalho a quatro mãos", ou seja, utilizando-se da ajuda de um auxiliar para que este possa minimizar movimentos antiergonômicos do cirurgião-dentista acelerando a maioria 
dos procedimentos. Delegar funções simples ao auxiliar traz resultados altamente satisfatórios no balanço final (RASIA, 2004).

Corroborando com a afirmação acima, verificou-se, no decorrer da pesquisa, que nas duas instituições durante a atividade acadêmica os alunos aprenderam a "trabalhar a quatro mãos" e se não o fazem é por opção própria.

Atualmente, (BARROS, 1995; POI; TAGLIAVINI, 1999), é absurda a idéia de um cirurgião-dentista trabalhar sem um auxiliar, mas há profissionais que ainda o fazem. A técnica de transferência de instrumentos, comumente utilizada na medicina, aumenta a produtividade e é pouco utilizada na odontologia. Portanto, (SALIBA; ELEUTÉRIO; SALIBA; MOIMAZ, 1998), não restam dúvidas de que a presença do auxiliar na prestação de serviços odontológicos públicos ou privados, e um ambiente físico apresentando equipamentos corretamente distribuídos compõem alguns dos elementos indispensáveis para o aumento da produtividade da equipe odontológica, e maior qualidade nos cuidados com o paciente, ao mesmo tempo que busca o bem-estar dos profissionais que fazem parte do grupo (RASIA, 2004).

Como formas de prevenção existem campanhas educativas sobre riscos à saúde na atividade dos cirurgiões-dentistas. Porém, no período de formação desses profissionais, é interessante notar que não há nas grades curriculares tópicos claramente específicos relativos a cuidados com a saúde desses trabalhadores, no sentido de informá-los, orientá-los e chamar sua atenção para a questão da manutenção de sua saúde, ainda segundo Andréia Faria (2003).

Assim, a prevenção vem chamando a atenção na vida das pessoas, das empresas e dos profissionais em geral, que sentem a necessidade da informação e da conscientização em busca de uma melhor qualidade de vida (MIYAMOTO et al., 1999; OLIVEIRA, 2006; CASTRO, 1999).

\section{Conclusão}

Há um predomínio do sexo feminino entre os acadêmicos de Odontologia, evidenciando que possuem outra atividade (professora) concomitante à prática acadêmica, além de realizarem atividades físicas (academia).

Nota-se também que nos testes de Tínel e Phalen os entrevistados, na condição de acadêmicos, têm alta prevalência de negatividade, ou seja, durante a prática acadêmica ainda não apresentam a Síndrome do Túnel do Carpo. Em relação à sintomatologia, ficou evidente que a dor em região cervical foi maior no sexo feminino e houve predomínio de assintomatologia no sexo masculino. Em conclusão ao check list, ficou evidente que o posto de trabalho, o tipo de trabalho e as ferramentas utilizadas apresentam um índice altíssimo para a ocorrência de LER/DORT.

A análise das fotos demonstrou que os acadêmicos adotam posturas e condutas que, ao longo dos anos de exercício da profissão, podem contribuir para o desenvolvimento da STC.

Portanto, a fisioterapia preventiva reforça a ideia de que investir na saúde do trabalhador preventivamente é muito mais vantajoso do que arcar com sua debilidade ocupacional (MIYAMOTO et al., 1999; OLIVEIRA, 2006; CASTRO, 1999).

De acordo com a literatura a presente pesquisa utilizou-se da entrega de material para a realização de alongamentos dos membros superiores (Anexo IV) como forma de prevenção para as LERs, principalmente a Síndrome o Túnel do Carpo (STC).

Os resultados do estudo mostraram que programas educativos podem surtir efeitos para o uso adequado das mãos e que estudos mais abrangentes devem ser desenvolvidos. 


\section{REFERÊNCIAS}

AGUÍRRE, V. L.; HEREDITA ALBARRÁN, A. L.; SALAS ARCE MINOR, E. Actitudes y práticas de los cirujanos dentistas com respecto al control de infecciones en la prática dental. Revista Asociación Dental Mexicana, v.50, n.5, p.285-90, sept.-oct. 1993.

CASTRO, S. L., FIGLIOLI, M. D. Ergonomia aplicada a dentística: avaliação da postura e posições de trabalho do cirurgião-dentista desta e da auxiliar odontológica em procedimentos restaurados. JBC j. bras. clín. estet. odontol., v.3, n.14, p. 56-62, 1999.

COUTO, H. A. Ergonomia aplicada ao trabalho: o manual técnico da máquina humana. V.2. Belo Horizonte: Ergoeditora, 1996.

. Ergonomia aplicada ao trabalho: o manual técnico da máquina humana. v. I. Belo Horizonte: Ergoeditora, 1995.

FARIA, A. V. C. Riscos no trabalho de cirurgiões-dentistas: informações e práticas referidas. (Tese de Mestrado em Saúde Pública). Rio de Janeiro: Fundação Oswaldo Cruz Escola Nacional de Saúde Pública, 2003. v. 98.

GOULD III, J. A. Fisioterapia na ortopedia e na medicina do esporte. 2. ed. São Paulo: Manole, 1998.

GRANDJEAN, E. Manual de ergonomia: adaptando o trabalho ao homem. 4. ed. Porto Alegre: Bookman, 1998.

IIDA, I. Ergonomia: projeto e produção. São Paulo: Edgard Blücher, 1997.

LEÃO, R. D.; PERES, C. C. Noções sobre DORT, lombalgia, fadiga, antropometria, biomecânica e concepção do posto de trabalho. 2004. (Monografia online). Disponível em:<www.tem.gov.br/Empregador/Segrau/Publicoes/ Ergonomia/Conteúdo/664>.

MAGEE, D. J. Avaliação músculoesquelética. 4.ed. São Paulo: Manole; 2005.

MARTINS, C. A., FADEL, M. A. V.; REGIS FILHO, G. I. Lesões por esforços repetitivos em cirurgiões-dentistas: um estudo de caso - Síndrome do Túnel do Carpo. Jornal Brasileiro de Clínica Odontológica Integrada, v.7, n. 41, p. 363-367, set/out. 2003.

OLIVEIRA, K. C.; GONÇALVES, R. D. Avaliação do cirurgião-dentista no seu ambiente de trabalho pela visão da fisioterapia preventiva. (Trabalho de Conclusão de curso). Goiás: Universidade Católica de Goiás, 2003.

POI, W. R.; REIS, L. A. S.; POI, I. C. L. Cuide bem dos seus punhos e dedos. Revista da APCD, v.53, n.2, p. 117-121, mar/abr. 1999.

RASIA, D. Quando a dor é do dentista: custo humano do trabalho de endodontistas e indicadores de DORT. (Tese de Mestrado em Psicologia). Brasília: Universidade de Brasília; 2004.
REGIS FILHO, G. I.; LOPES, M. C. Aspectos epidemiológicos e ergonômicos de lesões por esforço repetitivo em cirurgiões-dentistas. Revista da APCD., v.51, n.5, p. 469-474, set/out. 1997.

; MICHELS, G.; SELL I. Lesões por esforços repetitivos em cirurgiões-dentistas: aspectos clínicos - Parte I. Jornal Brasileiro de Clinica Odontológica Integrada. Ano 8, n. 43, p. 62-70, jan/fev 2004.

;______. Lesões por esforços repetitivos em cirurgiões-dentistas: aspectos clínicos - Parte II/II. Jornal Brasileiro de Clínica Odontológica Integrada, Ano 8, n. 44, p. 165-169, mar/abr 2004.

RUCKER, L. M.; SUNELL, S. Ergonomic risk factors associated with clinical dentristy. Journal of California Dental Association, v.30, n.2, p. 139-148, 2002. 